\title{
IMPACT OF TIBETAN PLATEAU SNOW COVER ON ABRUPT INTERDECADAL PRECIPITATION CHANGE OVER THE INDOCHINA PENINSULA IN THE MID-1990S
}

\author{
Yao Ha, Yimin Zhu*, Yijia Hu, Zhong Zhong \\ College of Meteorology and Oceanography, National University of Defense Technology, 211101 Nanjing, China - \\ hayao1986@yeah.net, zhuym@21cn.com,lgdxhuyijia@163.com, zhong_zhong@yeah.net
}

Commission III, WG III/8

KEY WORDS: Indochina Peninsula, Precipitation, Interdecadal Change, Snow Cover, Tibetan Plateau

\begin{abstract}
:
Abrupt interdecadal changes in summer precipitation (May - September) over the Indochina Peninsula in the past 40 years have been investigated based on the NCEP-NCAR reanalysis product over 1979-2013 and multiple precipitation datasets. The mechanism for the abrupt change is explored. Results indicate that an abrupt interdecadal change in summer precipitation over the Indochina Peninsula occurred in the middle 1990s, and the annual mean summer precipitation during 1994-2002 increased by about $10 \%$ compared to that during 1982-1993. The most significant precipitation change occurred in the central and northern peninsula. Further analysis reveals that the interdecadal decrease in snow cover over the Tibetan Plateau in the winter and spring contributed to the summer precipitation increase over the Indochina Peninsula. The decrease in snow cover over the Tibetan Plateau actually increased the thermal contrast between the Tibetan Plateau and the tropical Indian Ocean-northwestern Pacific, leading to intensified summer monsoon over the northwestern Pacific and the South China Sea. As a result, westerly anomalies occurred from the Bay of Bengal to the northwestern Pacific, while anomalous cyclonic circulation prevailed in the upper levels above East Asia. Correspondingly, the western Pacific subtropical high weakened and shifted eastward. Under the joint effects of the above circulation patterns, the atmosphere became wetter in the Indochina Peninsula and summer precipitation increased. Results of the present study provide a theoretical basis for the prediction of long-term summer precipitation change in the Indochina Peninsula.
\end{abstract}

\section{INTRODUCTION}

The spatial-temporal variation of summer precipitation over the Indochina Peninsula demonstrates multi-scale characteristics, and the interannual variability is the most significant. Previous studies have shown that the El Niño-Southern Oscillation (ENSO) is closely related to interannual variability of summer precipitation over the Indochina Peninsula (Xie et al., 2006, Wang et al., 2009, Hsu et al., 2014). In addition to the interannual variability, summer precipitation over the Indochina Peninsula also presents significant long-term variability characteristics. It has been confirmed that in the past 40 years, precipitation in Myanmar has increased significantly in early summer, which is closely related to early outbreak of the Indian monsoon. The early outbreak of summer monsoon is often accompanied by increased cyclone activities over the northern Indian Ocean and the Bay of Bengal, which contribute to the long-term precipitation change in the western Indochina peninsula (Ren et al., 2006). In the eastern coast of the Indochina Peninsula, changes in cyclone activity over the northwestern Pacific is highly correlated with summer precipitation changes in this area. In the past 30 years, the westward moving tropical cyclones originated in the South China Sea and the Philippine Sea frequently made landfall in central and northern Vietnam, which is favorable for summer precipitation increase along the coast (Ren et al., 2006, Zhong and $\mathrm{Hu}$ 2007, Wu et al., 2010). Nguyen-Thi et al. (2012) argued that since the 1990s, more frequent cyclone activities over the South China Sea have made significant contributions to the frequency increase in high intensity precipitation in Vietnam.
The Tibetan Plateau is known as the "third pole" of the earth, where the snow is characterized by high albedo and low thermal conductivity (Liu et al., 2014). Surface temperature anomalies induced by snow cover in the winter and spring over the Tibetan Plateau demonstrate strong seasonal persistence, which can alter temperature gradient in the lower troposphere between the plateau and its surrounding areas in the summer, and subsequently affects the thermal contrast and temperature and precipitation (Matsumoto, 1997). Therefore, snow cover over the Tibetan Plateau is regarded as an important precursor signal for the prediction of summer climate in East Asia. The Indochina Peninsula is located to the southeast of the Tibetan Plateau, adjacent to the South China Sea and the Bay of Bengal. Snow cover changes in the Tibetan Plateau would have potential impacts on the East Asian monsoon and summer precipitation variability over the Indochina Peninsula. Most of the previous studies more focused on interannual variability of summer precipitation over the Indochina Peninsula, and few studies are conducted to investigate the interdecadal changes of summer precipitation. In the present study, multiple precipitation datasets are used to reveal interdecadal variability of summer precipitation over the Indochina Peninsula. Based on this, the relationship between snow cover over the Tibetan Plateau in the early winter and spring and abrupt interdecadal change of summer precipitation in the Indochina Peninsula is analyzed. The possible mechanism behind the impact of winter and spring snow cover over the Tibetan Plateau on interdecadal variability of summer precipitation in the Indochina Peninsula is explored. This study provides scientific evidences for the

\footnotetext{
* Corresponding author
} 
prediction of summer precipitation over the Indochina Peninsula.

\section{DATA AND METHOD}

In order to verify the abrupt interdecadal changes in summer precipitation over the Indochina Peninsula, four precipitation datasets, i.e., the global $1^{\circ} \times 1^{\circ}$ precipitation reanalysis product issued by Global Precipitation Climate Center, the $2.5^{\circ} \times 2.5^{\circ}$ merged precipitation dataset issued by Climate Prediction Center, the $2.5^{\circ} \times 2.5^{\circ}$ precipitation dataset provided by Global Precipitation Climate Program, the NOAA $2.5^{\circ} \times 2.5^{\circ}$ reconstructed precipitation dataset, are analyzed in the present study. Since the summer monsoon usually outbreaks in May over South Asia and the South China Sea and the rain season starts in the Indochina Peninsula, the study period is over May-September. Monthly mean snow cover data on global $192 \times 94$ Gaussian grids are from the NOAA Environmental Center. The atmospheric environmental fields are extracted from the NCEP/NCAR monthly and daily reanalysis products, which include temperature, wind speed, relative humidity, geopotential height, and vertical velocity on 17 pressure levels and sea level pressure, etc.

Due to the uncertainty in snow cover data before 1975 and the distinct interdecadal change of atmospheric circulation in East Asia that occurred in the middle to late $1970 \mathrm{~s}$, the period of 1979-2013 is selected for the present study. The regional mean snow cover averaged from previous December to present February over the area of $\left(80^{\circ}-100^{\circ} \mathrm{E}, 25^{\circ}-35^{\circ} \mathrm{N}\right)$ is calculated, and the reverse of this mean snow cover area is defined to be to the Tibetan Plateau winter snow cover index (TPSC). Similarly, the spring snow cover index is defined as the reverse of regional mean snow cover area over March-May.

In order to exclude the verification uncertainty of the abrupt interdecadal change induced by a single method, the Lepage test and sliding t-test are used to extract signals of abrupt interdecadal changes in the four datasets mentioned above. The Lepage test is a nonparametric statistical test method, which has been widely applied for diagnostic analysis and abrupt climate change test. Sliding t-test is a commonly used method to test points of abrupt changes and the significance of these changes. Ha et al. (2016) presented a detailed description of the above methods. In addition, composite analysis and regression analysis have been applied in the present study to investigate the relationship of abrupt interdecadal changes in summer precipitation and circulation fields with the TPSC in the winter and spring.

\section{THE ABRUPT INTERDECADAL CHANGE IN SUMMER PRECIPITATION OVER THE INDOCHINA PENINSULA IN THE 1990S}

Takahashi and Yasunari (2006) found that precipitation in the Indochina Peninsula presents a bimodal distribution in the rainy season with the peak values occurring during May-June and August-September, corresponding to the summer monsoon outbreak and the peak time of tropical cyclone activities in the western Pacific. Figure 1 displays time series of normalized precipitation during May-September for the period of 19792013. Due to the joint influences of the Indian summer monsoon and the South China Sea summer monsoon, summer precipitation in the Indochina Peninsula demonstrates a distinct interannual oscillation, and the correlation coefficient between time series from various datasets can be up to above 0.6, suggesting that precipitation from the four datasets show similar interannual variability. In order to examine whether there exist interdecadal changes in summer precipitation over the Indochina Peninsula, 11-year moving average is applied to the time series of precipitation. Figure 1 shows that abnormally low precipitation persisted from the early 1980s to mid-1990s; since the mid-1990s, precipitation became higher than normal. This result indicates that an abrupt interdecadal change of summer precipitation occurred in the mid-1990 abnormally high. s over the Indochina Peninsula, and precipitation changed from abnormally low to abnormally high. Results based on the four datasets are highly consistent, indicating that the abrupt interdecadal precipitation increase is truthful.
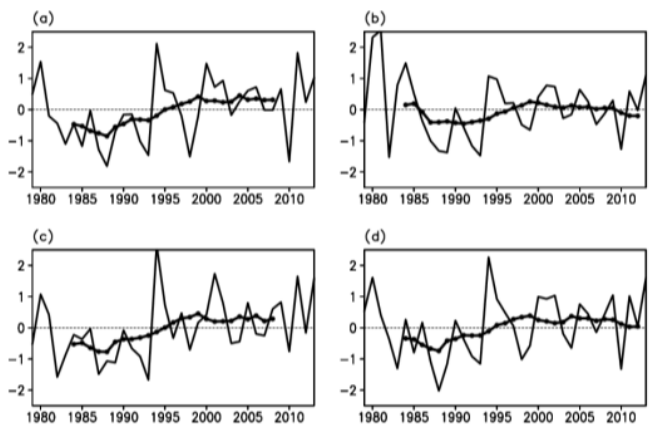

Figure 1. Time series of summer rainfall anomalies (thin lines) and their 11-yr running mean (think lines) over the Indochina Peninsula based on the (a) GPCC, (b) CMAP, (c) GPCP and (d) NOAA Recon datasets.

In order to determine the exact time of the abrupt change, the Lepage test and sliding t-test are implemented for significance test of the abrupt interdecadal precipitation changes for all the four datasets. Results are displayed in Figure 2, which shows that the two methods yield consistent results, except that the Lepage method shows the abrupt change occurred in the late 1990 s based on the CMAP dataset. All other results suggest that $1993 / 94$ is the time of abrupt interdecadal change of summer precipitation in the past 40 years. Furthermore, all the results are significant at the $95 \%$ confidence level. Based on the time of abrupt change, the study period is divided into pre- (19821993) and after-abrupt change (1994-2002) periods. Precipitation and associated circulation characteristics are compared between the two periods.

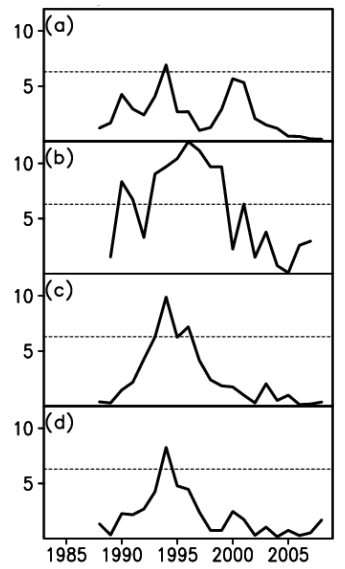


Figure 2. Statistics of moving $t$-test for the time series of summer rainfall over the Indochina Peninsula based on the (a) GPCC, (b) CMAP, (c) GPCP and (d) NOAA Recon datasets.

Figure 3 shows the spatial distribution of interdecadal precipitation difference over the Indochina Peninsula between 1994-2002 and 1982-1993. The interdecadal precipitation anomalies shown in GPCC, CMAP and NOAA reconstructed dataset are consistent. Significant positive anomalies are found over central and northern Indochina Peninsula, while the positive anomalies in the southern Indochina Peninsula are not significant (Figures $3 \mathrm{a}, 3 \mathrm{~b}$ and $3 \mathrm{~d}$ ). Significant positive precipitation anomalies are distributed over larger area for GPCP, and the values of anomaly are slightly larger than those in the other three datasets (Figure 3c). Overall, summer precipitation increased by nearly $10 \%$ over $1994-2002$ than that over 1982-1993. All the four datasets present the abrupt interdecadal precipitation increase in 1993/94, suggesting that the abrupt change is truthful. In the next, environmental fields that affect summer precipitation over the Indochina Peninsula are analyzed.
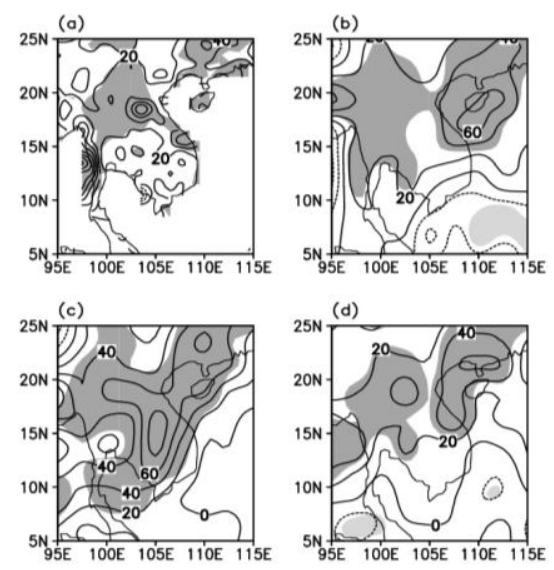

Figure 3. Epochal differences (2002-1994 minus 1982-1993) in summer rainfall based on the (a) GPCC, (b) CMAP, (c) GPCP and (d) NOAA Recon datasets. Values exceeding the 95\% confidence level are shaded.

Figure 4 presents differences in interdecadal circulation and environmental fields between 1994-2002 and 1982-1993 over East Asia. Figure 4a shows that, compared with that during $1982-1993$, southeasterly anomalies occurred over $10^{\circ}-20^{\circ} \mathrm{N}$ from the Bay of Bengal to the northwestern Pacific after 1994 , corresponding to the intensified summer monsoon over the South China Sea and northwestern Pacific. Cyclonic circulation anomaly prevailed in the lower troposphere from $15^{\circ} \mathrm{N}$ to subtropical East Asia. In particular, a significant cyclonic circulation anomaly developed above the Indochina Peninsula. Corresponding to this circulation characteristic, geopotential height anomalies in the mid troposphere above this area were negative with the negative anomaly center located near $130^{\circ} \mathrm{E}$ to the east of Taiwan Island (Figure $4 \mathrm{~b}$ ), indicating that the western Pacific subtropical high was weakened. Note that abnormally strong summer monsoon winds over the northwestern Pacific and abnormally weak western Pacific subtropical high both are favorable for precipitation increase in the Indochina Peninsula and northwestern Pacific. This result is consistent with the mechanism proposed by Zou et al. for the influence of the western Pacific subtropical high on water vapor transport over the tropical Indian Ocean and western Pacific. In addition, it is worth noting that the negative geopotential height anomalies shown in Figure 4b cannot pass the significance test at the $95 \%$ confidence level, which is possibly related to the large interannual variability of the western Pacific subtropical high.

Precipitation changes in the tropics are closely related to local thermal-dynamic conditions ( $\mathrm{Li}$ et al., 2013). In order to further clarify the impact of local environmental fields on summer precipitation in the Indochina Peninsula, interdecadal differences in relative vorticity in the lower troposphere and vertical velocity and relative humidity in the middle troposphere are displayed in Figures $4 \mathrm{c}-4 \mathrm{e}$. Compared with that in the former decade, cyclonic vorticity anomaly prevailed in the lower troposphere above the Indochina Peninsula in the latter decade (Figure 4c), while the middle troposphere was abnormally wetter with anomalous ascending motions (Figures $4 \mathrm{~d}$ and $4 \mathrm{e}$ ). Meanwhile, water vapor flux over the entire troposphere demonstrated significant cyclonic shear anomalies (Figure 4f), leading to water vapor flux convergence over the Indochina Peninsula and South China (Ha et al., 2016). Precipitable water subsequently increased (Figures $4 \mathrm{~g}$ and $4 \mathrm{~h}$ ). The above interdecadal differences of environmental fields all exceed the 95\% confidence level. Apparently, such a thermaldynamic condition was favorable for the increase of precipitation and convective activities during 1994-2002, and was directly responsible for the abrupt interdecadal change in precipitation that occurred in 1993/94.
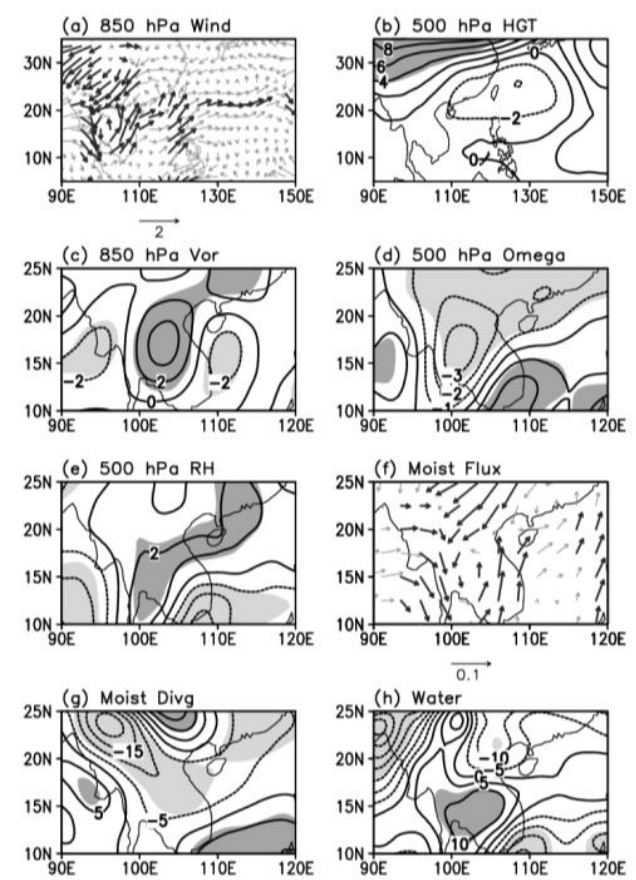

Figure 4. Epochal differences (2002-1994 minus 1982-1993) in (a) $850 \mathrm{hPa}$ wind $\left(\mathrm{m} \mathrm{s}^{-1}\right)$, (b) $500 \mathrm{hPa}$ geopotential height (gpm), (c) $850 \mathrm{hPa}$ vorticity (contours $10^{-6} \mathrm{~s}^{-1}$ ), (d) $500 \mathrm{hPa}$ vertical pressure velocity $\left(\mathrm{Pa} \mathrm{s}^{-1}\right)$, (e) $500 \mathrm{hPa}$ relative humidity (\%), (f) moisture flux $\left(\mathrm{g} \mathrm{m}^{-1} \mathrm{~s}^{-1}\right),(\mathrm{g})$ moisture flux divergence $\left(10^{-7} \mathrm{~g}\right.$ $\left.\mathrm{m}^{-2} \mathrm{~s}^{-1}\right)$ and (h) atmospheric precipitable water $\left(10^{-2} \mathrm{~g} \mathrm{~m}^{-2}\right)$. Values exceeding the $95 \%$ confidence level are shaded. 


\section{IMPACT TIBETAN PLATEAU SNOW COVER ON ABRUPT INTERDECADAL CHANGE OF PRECIPITATION OVER THE INDOCHINA PENINSULA}

Due to the unique topographic effects, the Tibetan Plateau has critical impacts on weather and climate over east Asia and even the entire world. Particularly, snow cover change in the Tibetan Plateau could alter the thermal condition of the land surface, while the atmospheric response to the changes in surface thermal condition would significantly modulate the East Asian monsoon and Indian monsoon. In this section, we will focus on the discussion of possible impacts of snow cover over the Tibetan Plateau on the abrupt interdecadal precipitation change in the Indochina Peninsula.

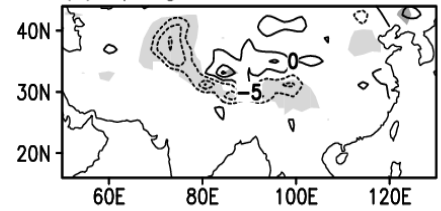

Figure 5. Epochal differences (2002-1994 minus 1982-1993) in snow cover over the Tibetan Plateau. Values exceeding the $95 \%$ confidence level are shaded.

Figure 5 shows interdecadal differences in winter and spring snow cover over the Tibetan Plateau between 1994-2002 and 1982-1993. In the winter, significant negative snow cover centers occurred in the eastern and western Tibetan Plateau, while positive center was found in the northern Tibetan plateau. However, the positive anomalies didn't pass the significance test. In the spring, significant negative snow cover anomalies occurred over the western Tibetan Plateau and Himalayas, while positive anomalies in the central plateau rapidly decreased. Overall, the winter and spring snow cover over the Tibetan Plateau experienced distinct interdecadal decreases. Meanwhile, note that the winter and spring TPSCs are highly correlate, suggesting that the abnormal state of snow cover on the plateau is very persistent, and can maintain from winter to spring and even early summer. Xiao and Duan (2016) proposed that the winter and spring snow cover over the western Tibetan Plateau and Himalaya can maintain longer time than that in other regions, and thus has more significant impacts on East Asian monsoon through modulating atmospheric circulation and water vapor transport. The spring snow cover anomalies shown in Figure 5 were exactly located in the western Tibetan Plateau and the mountainous area to its south. The temporal consistency between interdecadal decrease in winter and spring snow cover over the Tibetan Plateau and interdecadal increase in summer precipitation over the Indochina Peninsula indicates that changes in the spring and winter snow cover over the plateau might have impacts on precipitation anomalies in the Indochina Peninsula.
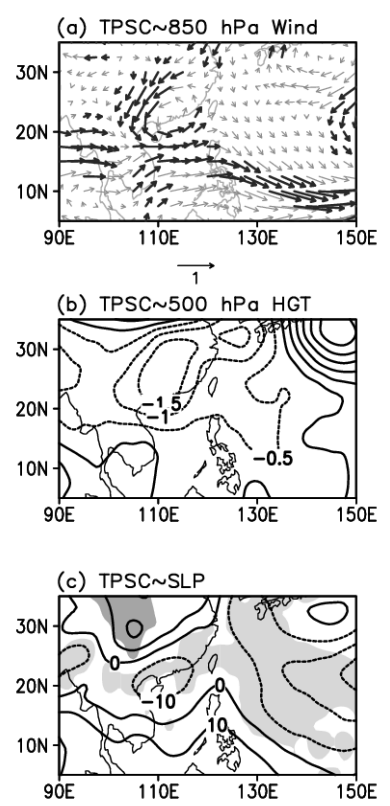

Figure 6. Regression upon snow cover index over the Tibetan Plateau for (a) $850 \mathrm{hPa}$ wind $\left(\mathrm{m} \mathrm{s}^{-1}\right)$, (b) $500 \mathrm{hPa}$ geopotential height (gpm) and (c) sea surface pressure $(\mathrm{hPa})$ in the period 1979-2012.Values exceeding the 95\% confidence level are bold wind vectors or shaded.

To address the above issue, and considering the fact that snow cover in the western plateau and mountains on the southern edge have important impacts on East Asia summer monsoon, $850 \mathrm{hPa}$ wind, $500 \mathrm{hPa}$ geopotential height and sea level pressure are regressed against the spring TPSC during 19822002 to explain summer circulation response in East Asia to spring snow cover in the Tibetan Plateau. Figure 6 shows that when spring snow cover is abnormally low in the plateau, significant westerly anomalies prevail in the summer from the Bay of Bengal to the tropical Pacific, and East Asia from $15^{\circ} \mathrm{N}$ northward is under the control of cyclonic anomaly (Figure 6a). Meanwhile, the western Pacific subtropical high shifts westward and becomes weak, while the negative geopotential height anomaly center is located in South China (Figure 6b). Sea level pressure (SLP) is distinctly lower over the Indochina Peninsula, the northern South China Sea and the western Pacific. In contrast, SLP is significantly high over land areas of East Asia including the Tibetan Plateau (Figure 6c). The above regression analysis results are basically consistent with interdecadal anomalies of large circulation shown in Figure 4a and $4 \mathrm{~b}$, indicating that summer precipitation in Indochina Peninsula is closely correlated with snow cover in the plateau. Previous observations and modeling studies indicate that a stronger than normal heat source in the Tibetan Plateau would increase the thermal contrast between the plateau and the land area to its east and the ocean area to its south. As a result, the South China Sea monsoon would outbreak earlier, while the East Asian summer monsoon and the South China Sea summer monsoon both would intensify. This is consistent with the result of Chan et al. (2016) that the TPSC and other remote force can affect summer precipitation in East Asia. It also agrees with the mechanism proposed by $\mathrm{Ha}$ et al. (2014) that the TPSC can modulate tropical cyclone activities over the northwestern Pacific and the South China Sea. Results of the present study are consistent with those of previous studies. Following the decrease in snow cover over the Tibetan Plateau, the thermal 
contrast between the Indochina Peninsula and the Tibetan Plateau increases distinctly, leading to intensified summer monsoon over the northwestern Pacific and the South China Sea Meanwhile, the western pacific subtropical high shifts eastward and becomes weak than normal. All the above large-scale circulation patterns are favorable for more precipitation in the Indochina Peninsula.
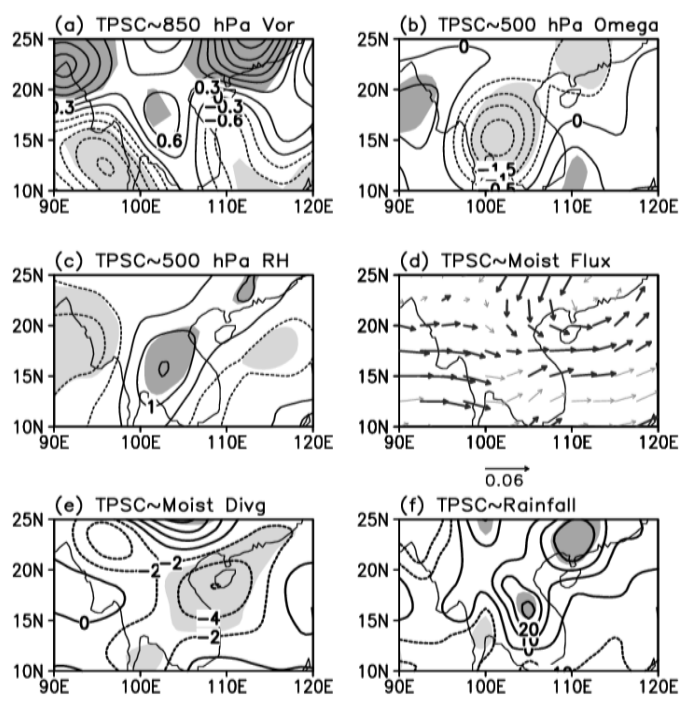

Figure 7. Regression upon snow cover index over the Tibetan Plateau for (a) $850 \mathrm{hPa}$ vorticity (contours $10^{-6} \mathrm{~s}^{-1}$ ), (b) $500 \mathrm{hPa}$ vertical pressure velocity $\left(\mathrm{Pa} \mathrm{s}^{-1}\right)$, (c) $500 \mathrm{hPa}$ relative humidity (\%), (d) moisture flux divergence $\left(10^{-7} \mathrm{~g} \mathrm{~m}^{-2} \mathrm{~s}^{-1}\right)$, (e) moisture flux divergence $\left(10^{-7} \mathrm{~g} \mathrm{~m}^{-2} \mathrm{~s}^{-1}\right)$ and (f) atmospheric precipitable water $\left(10^{-2} \mathrm{~g} \mathrm{~m}^{-2}\right)$ in the period 1979-2012. Values exceeding the $95 \%$ confidence level are bold wind vectors or shaded.

The summertime environmental fields over the Indochina Peninsula are regressed upon the spring TPSC, and the results are similar to large-scale circulation anomalies. As shown in Figure 7, when snow cover decreases in the Tibetan Plateau, cyclonic circulation anomaly develops in the lower troposphere over the Indochina Peninsula (Figure 7a). Ascending motions are abnormally active over the central peninsula (Figure $7 b$ ), and the atmospheric moisture content increases significantly (Figure 7c). Cyclonic circulation anomaly develops over the entire troposphere (Figure 7d), accompanied with water vapor flux convergence (Figure 7e). The above results are consistent with the interdecadal differences in environmental fields shown in Figures $4 \mathrm{c}-4 \mathrm{~g}$. Figure $7 \mathrm{f}$ presents spatial distribution of coefficient of NOAA reconstructed precipitation regressed onto the spring TPSC. Corresponding to the changes in environmental fields, decreases in snow cover over the Tibetan Plateau are accompanied with increases in precipitation over the Indochina Peninsula, with the significant positive precipitation anomaly center located in central peninsula. Regressions of the other three precipitation datasets onto the TPSC yield similar results to that shown in Figure 7f. In addition, circulation and environmental fields over East Asia are regressed onto winter TPSC, and the coefficient distribution (Figure not shown) is similar to Figure 6 and 7. The above results indicate that the snow cover decrease over the Tibetan Plateau in the mid-1990s directly leads to the abrupt interdecadal precipitation increase over East and Southeast Asia by affecting the intensity of the East Asian summer monsoon.

\section{CONCLUSIONS AND DISCUSSION}

Abrupt interdecadal precipitation changes during MaySeptember in the past 40 years are investigated in the present study, and possible impacts of snow cover changes over the Tibetan Plateau on the abrupt precipitation change in the Indochina Peninsula are revealed. Results indicate that an abrupt interdecadal summer precipitation change over the Indochina Peninsula occurred in the middle 1990s, and the annual mean summer precipitation during 1994-2002 increased by about $10 \%$ compared to that during 1982-1993. The most significant precipitation change occurred in the central and northern peninsula. Accompanied with the abrupt precipitation increase, a cyclonic circulation anomaly prevailed in the lower troposphere above the peninsula, while the water vapor transport over the Bay of Bengal increased. Water vapor convergence and ascending motions abnormally intensified over most areas of the peninsula. Further analysis reveals that snow cover over the Tibetan Plateau decreased significantly in the winter since the mid-1990s, which increased the thermal contrast between the Tibetan Plateau and the tropical Indian Ocean-northwestern Pacific, leading to early onset of summer monsoon over the northwestern Pacific and the South China Sea. As a result, the summer monsoon intensified and westerly anomalies occurred from the Bay of Bengal to the northwestern Pacific. Meanwhile, the western Pacific subtropical high weakened and shifted eastward. Correspondingly, East Asia was under the control of cyclonic circulation anomaly. Under the joint effects of the above circulation patterns, the atmosphere became wetter over the Indochina Peninsula and precipitable water increased, leading to interdecadal precipitation increase there.

The present study clarifies the impact of Tibetan Plateau snow cover changes in the winter and spring on the abrupt interdecadal summer precipitation change over the Indochina Peninsula. The reverse changes between snow cover in the Tibetan Plateau and precipitation in the Indochina Peninsula have been revealed. Results of the present study provide a theoretical basis for the prediction of long-term summer precipitation change over this region. Note that in addition to the snow cover in the Tibetan Plateau, some other factors may also affect long-term precipitation change in the Indochina Peninsula. For example, summer precipitation and environmental fields have been regressed upon the TPSC in this study. Although the spatial distribution of regression coefficient is consistent with the pattern of interdecadal changes of environmental fields including precipitation, the magnitude is smaller than that of the interdecadal anomalies. This indicates that changes in snow cover over the Tibetan Plateau can only partly explain the abrupt interdecadal precipitation change that occurred in the mid-1990s over the Indochina peninsula. Previous studies have revealed that long-term global sea surface temperature (SST) changes have potential impacts on abrupt interdecadal precipitation changes in East and Southeast Asia. For this reason, we also examine the interdecadal SST changes in the winter, spring and summer around 1993/94. Preliminary results show that negative SST anomalies occurred over the central eastern Pacific in the winter and spring, right before the occurrence of the abrupt summer precipitation change in the Indochina Peninsula. The negative SST anomalies gradually disappeared in the summer. Meanwhile, positive SST anomalies appeared over the North Atlantic. Studies of Gao et al. (2013) suggest that positive SST anomalies over the North Atlantic can trigger planetary Rossby waves, which affect the western Pacific subtropical high and subsequently influence tropical 
cyclone activities in East Asia and summer precipitation in Southwest China. Chan et al. (2016) confirmed the forcing of North Atlantic SST anomalies on the western Pacific subtropical high. In addition, Ha et al. (2014) found that more tropical cyclones with longer life-span and stronger intensity have originated over the South China Sea since 1994, and most of these tropical cyclones frequently made landfall in Beibu Gulf and central and northern Vietnam. After landing, these cyclones could still last for about 12 hours before they gradually disappeared. Considering the synchronization of abrupt interdecadal changes in tropical cyclone activity in the South China Sea and summer precipitation in the Indochina Peninsula, is it possible that nearshore activities of TC and TC landings may change precipitation variability in the Indochina Peninsula? Could the tropical cyclone activities in the northwestern Pacific and the South China Sea affect the interdecadal increase in summer precipitation in the Indo-China Peninsula after 1994? In the future, we will combine numerical model results to quantitatively evaluate contribution of snow cover over the Tibetan Plateau to summer precipitation in the Indochina Peninsula, and analyze impacts of SST anomalies in the equatorial Pacific and North Atlantic Oceans and tropical cyclone activities in the Northwest Pacific on abrupt interdecadal changes in summer precipitation over the peninsula.

\section{ACKNOWLEDGEMENTS}

This work is sponsored jointly by the National Natural Science Foundation of China (41975090, 41430426, 41505058), Scientific Research Program of National University of Defense Technology (ZK17-03-22) and the Jiangsu Collaborative Innovation Center for Climate Change in Nanjing University.

\section{REFERENCES}

Chan, T. C., Hsu, H. H., Hong, C. C., 2016. Enhanced influences of tropical Atlantic SST on WNP-NIO atmosphereocean coupling since the early 1980s. J Clim, 15, 6509-6525.

Gao, Y., Wang, H., Li, S., 2013. Influences of the Atlantic Ocean on the summer precipitation of the southeastern Tibetan Plateau. J Geophys Res, 118, 3534-3544.

Ge, F., Zhi, X. F., Babar, Z. A., Tang, W. W., Chen, P., 2017. Interannual variability of summer monsoon precipitation over the Indochina Peninsula in association with ENSO. Theor Appl Climatol, 128, 523-531.

Ha, Y., Zhong, Z., Chen, H., Hu, Y., 2016. Out-of-phase decadal changes in boreal summer rainfall between YellowHuaihe River Valley and southern China around 2002/2003. Clim Dyn, 47, 137-158.

Ha, Y., Zhong, Z., Sun, Y., Lu, W., 2014. Decadal change of South China Sea tropical cyclone activity in mid-1990s and its possible linkage with intraseasonal variability. J Geophys Res, 119, 5331-5344.

Hsu, H. H., Zhou, T., Matsumoto, J., 2014. East Asian, Indochina and Western North Pacific Summer Monsoon-an update. Asia-Pac J Atmos Sci, 50, 45-68.

Li, X., Zhou, W., Li, C., Song, J., 2013. Comparison of the annual cycles of moisture supply over southwest and southeast China. J Clim, 26, 10139-10158.
Liu, G., Wu, R. G., Zhang, Y. Z., Nan, S. L., 2014. The summer snow cover anomaly over the Tibetan Plateau and its association with simultaneous precipitation over the mei-yubaiu region. Adv Atmos Sci, 31, 755-764.

Matsumoto, J., 1997. Seasonal transition of summer rainy season over Indochina and adjacent monsoon region. Adv Atmos Sci, 14, 231-245.

Nguyen-Thi, H. A., Matsumoto, J., Ngo-Duc, T., Endo, N., 2012. A climatological study of tropical cyclone rainfall in Vietnam. Sci Online Lett Atmos, 8, 41-44.

Ren, F., Wu, G., Dong, W., Wang, X., Wang, Y., Ai, W., Li, W., 2006. Changes in tropical cyclone precipitation over China. Geophys Res Lett, 33, L20702.

Takahashi, H. G., Yasunari, T., 2006. A climatological monsoon break in rainfall over Indochina - A singularity in the seasonal march of the Asian summer monsoon. J Clim, 19, 1545-1556.

Wang, B., Huang, F., Wu, Z., Yang, J., Fu, X., Kikuchi, K., 2009. Multi-scale climate variability of the South China Sea monsoon, A review. Dyn Atmos Oceans, 47, 15-37.

Wu, C. H., Hsu, H. H., 2016. Role of the Indochina Peninsula narrow mountains in modulating the East Asian-western North Pacific summer monsoon. J Clim, 29, 4445-4459.

Wu, R. G., Wen, Z., Yang, S., Li, Y., 2010. An interdecadal change in southern China summer rainfall around 1992/93. J Clim, 23, 2389-2403.

Xiao, Z., Duan, A., 2016. Impacts of Tibetan Plateau snow cover on the interannual variability of the East Asian summer monsoon. J. Clim, 29, 8495-8514.

Xie, S.-P., Xu, H. M., Saji, N. H., Wang, Y., 2006. Role of narrow mountains in large-scale organization of Asian monsoon convection. J. Clim, 19, 3420-3429.

Zhong, Z., Hu, Y., 2007. Impacts of tropical cyclones on the regional climate, An East Asian summer monsoon case. Atmos Sci Lett, 8, 93-99. 